I am most thankful to Dr V. Vand, who taught me the fundamentals of this sort of work, and to Prof. G. Hägg and Prof. E. Stenhagen for their advice and interest. Mr S. E. Flygar has carried out much of the computations and I am indebted to him for his careful work.

\section{References}

BRIIL, R. \& MEYER, K. H. (1928). Z. Kristallogr. 67, 570.

Bunn, C. W. (1939). Trans. Faraday Soc. 35, 482.

Francis, F., Piper, S. H. \& Malikin, T. (1930). Proc. Roy. Soc. A, 128, 214.

HäGG, G. \& LAURENT, T. (1946). J. Sci. Instrum. 23, 155.

Lange, J. J. DE, Robertson, J. M. \& Woodward, I. (1939). Proc. Roy. Soc. A, 171, 398.

McWeeny, R. (1951). Acta Cryst. 4, 513.

Meyer, J. D. \& Reid, E. E. (1933). J. Amer. Chem. Soc. 55,1574 .

Acta Cryst. (1954). 7, 532
Morley, W. M. \& VAND, V. (1949). Nature, Lond. 163, 285.

Müller, A. (1927). Proc. Roy. Soc. A, 114, 542.

MÜller, A. \& Lonsdale, K. (1948). Acta Cryst. 1, 129.

Stenhagen, E. \& Sydow, E. von (1953). Arkiv Kemi, $6,309$.

Stenhagen, E., VAND, V. \& Sim, A. (1952). Acta Cryst. 5,695 .

Thibaud, J. \& DUPRÉ LA Tour, F. (1932). J.Chim.Phys. 29, 164.

Trimlat, J.J. \& Hirsch, Th. v. (1932). C. R. Acad. Sci., Paris, 195, 215.

Vainshtein, B. K. \& Pinsker, Z. G. (1950). Dokl. Akad. Nauk, SSSR. 72, 53.

VAND, V. (1951). Acta Cryst. 4, 104.

Vand, V., Aitken, A. \& Campbell, R. K. (1949). Acta Cryst. 2, 398.

VAND, V. \& BeLl, I. P. (195I). Acta Cryst. 4, 465.

VAND, V., MORLEY, W. M. \& LOMER, T. R. (1951). Acta Cryst. 4, 324.

\title{
The Grystal Structure of Samarium*
}

\author{
By A. H. Daane, R. E. Rundle, H. G. Smith and F. H. Spedding \\ Institute for Atomic Research and Department of Chemistry, Iowa State College, Ames, Iowa, U.S.A.
}

(Received 25 September 1953 and in revised form 3 February 1954)

\begin{abstract}
The crystal structure of samarium is rhombohedral; $a=8.996 \AA, \alpha=23^{\circ} 13^{\prime}, Z=3$. The atomic positions are $0,0,0 ; \frac{2}{9}, \frac{2}{9}, \frac{2}{9}$; and $\frac{7}{9}, \frac{7}{9}, \frac{7}{9}$. Single-crystal data require a disordered (or submicroscopically twinned) structure where half of the unit cells are rotated $180^{\circ}$ about the threefold axis with respect to the other half. The hexagonal lattice constants are $a=3 \cdot 621 \pm 0 \cdot 007 \AA$, $c=26 \cdot 25 \pm 0 \cdot 05 \AA ; Z=9$.
\end{abstract}

\section{Introduction}

The method of preparation and the large, rhombohedral unit cell for samarium were reported recently by Daane, Dennison \& Spedding (1953). Single crystals showed clearly that some sort of disorder was present in the structure, and an investigation of the structure and nature of the disorder was made. Since the completion of this work a report of the structure derived from powder data has been published by Ellinger \& Zachariasen (1953). We report here a brief confirmation of the structure from single-crystal data, together with the nature of the disorder, which was not discovered from the powder data.

\section{Experimental data}

Weissenberg and precession photographs were taken

* Contribution No. 322 from the Institute for Atomic Research and Department of Chemistry, Iowa State College, Ames, Iowa. Work was performed in the Ames Laboratory of the Atomic Energy Commission. with $\mathrm{Cu} K \alpha$ and Mo $K \alpha$ radiation, respectively, using single crystals picked from a sample of $99 \%$ purity. Precession data, using small crystals and Mo radiation, indicated a Laue symmetry $D_{6 h}$.

The reflections were indexed on a hexagonal cell with lattice constants

$$
a=3 \cdot 621 \pm 0 \cdot 007 \AA, c=26 \cdot 25 \pm 0 \cdot 05 \AA .
$$

(These values were obtained from a precession photograph of $(h 0 . l)$ data with a calcite diffraction pattern superimposed on the film.) The observed bulk density is $7.53 \mathrm{~g} . \mathrm{cm} .^{-3}$, while the calculated X-ray density is 7.54 g.cm..$^{-3}$ assuming 9 atoms per unit cell.

The observed reflections may be divided into two types:

Type I: $(h k . l)$-for $h-k=3 n$, only with $l=9 n$;

Type II: $(h k . l)$-for $h-k \neq 3 n$, only with $l \neq 3 n$.

In addition it was observed that the intensities of reflections of Type I are the same, except for the normal decline due to reduced scattering power of the 
Table 1. Comparison of some $F / f$ values with the observed intensities for the two types of unit cells

$\begin{array}{cccl}h k . l & F_{1} / f & F_{2} / f & I_{o} \\ 00.9 & 9 & 9 & s+ \\ 10.1 & 0 & 4 \cdot 04 & m \\ 10 . \overline{1} & 4 \cdot 04 & 0 & m \\ 10.2 & -2 \cdot 64 & 0 & w \\ 10 . \overline{2} & 0 & -2 \cdot 64 & w \\ 10.3 & 0 & 0 & \text { Nil } \\ 10 . \overline{3} & 0 & 0 & \text { Nil } \\ 10.4 & 0 & 7 \cdot 60 & s- \\ 10 . \overline{4} & 7 \cdot 60 & 0 & 8- \\ 10.5 & 7 \cdot 60 & 0 & s- \\ 10 . \overline{5} & 0 & 7 \cdot 60 & s- \\ 10.6 & 0 & 0 & \text { Nil } \\ 10 . \overline{6} & 0 & 0 & \text { Nil } \\ 10.7 & 0 & -2 \cdot 64 & w- \\ 10 . \overline{7} & -2 \cdot 64 & 0 & w- \\ 10.8 & 4 \cdot 04 & 0 & m- \\ 10 . \overline{8} & 0 & 4 \cdot 04 & m- \\ 10.9 & 0 & 0 & \text { Nil } \\ 10.9 & 0 & 0 & \text { Nil }\end{array}$

atoms with increasing Bragg angle and the Lorentz polarization factor. The same is true for the $(h k . l)$ and $\left(h, k, ., l_{ \pm} 9\right)$ reflections of Type II. A small amount of streaking in the $c$ direction was observed between the Type II reflections, suggesting some type of disorder.

\section{The structure and disorder}

The special extinctions above, as well as considerations of possible types of close-packed structures, lead at once to the structure reported by Ellinger \& Zachariasen, with atomic positions $\left(0,0,0 ; 0,0, \frac{2}{9} ; 0,0, \frac{7}{9}\right)+$ $\left(0,0,0 ; \frac{1}{3}, \frac{2}{3}, \frac{1}{3} ; \frac{2}{3}, \frac{1}{3}, \frac{2}{3}\right)$, represented by the packing sequence

$$
\frac{A}{c / a b} \quad \frac{B}{a b c} \quad \frac{C}{b c a} \quad \frac{A}{c / a b} \text {. }
$$

The structure is rhombohedral with the space group $R \overline{3} m$. The rhombohedral axes are

$$
a=8.996 \AA, \alpha=23^{\circ} 13^{\prime} .
$$

Single-crystal intensity data are not in agreement with this structure; indeed, even the symmetry of the

Table 2. Comparison of the observed structure factors with the calculated structure factors of the proposed structure

\begin{tabular}{|c|c|c|c|c|c|c|c|}
\hline$h k . l$ & $\left|F_{0}\right|$ & $F_{c}$ & $F_{R} \dagger$ & $h k . l$ & $\left|F_{o}\right|$ & $F_{c}$ & $F_{R} \dagger$ \\
\hline $00 . l$ & & & & 7 & 130 & -106 & -106 \\
\hline 9 & 724 & 659 & 932 & 8 & 163 & 161 & 161 \\
\hline 18 & 546 & 512 & 724 & 10 & 165 & 157 & 157 \\
\hline 27 & 425 & 411 & 581 & 11 & 116 & -101 & -101 \\
\hline \multirow[t]{2}{*}{36} & 352 & 346 & 489 & 13 & 272 & 283 & 283 \\
\hline & & & & 14 & 275 & 278 & 278 \\
\hline $10 . l$ & & & & 16 & 93 & -94 & -94 \\
\hline I & 239 & 214 & 214 & 17 & 116 & 141 & I4I \\
\hline 2 & 198 & -139 & -139 & 19 & 114 & 136 & 136 \\
\hline 4 & $\begin{array}{l}190 \\
425\end{array}$ & $\begin{array}{r}-139 \\
\mathbf{3 9 3}\end{array}$ & $\begin{array}{r}-159 \\
393\end{array}$ & 20 & 92 & -87 & -87 \\
\hline 5 & $\begin{array}{l}430 \\
430\end{array}$ & $\begin{array}{l}590 \\
387\end{array}$ & $\begin{array}{l}590 \\
\mathbf{3 8 7}\end{array}$ & 22 & 194 & 243 & 243 \\
\hline 7 & 182 & -131 & $\begin{array}{r}001 \\
-131\end{array}$ & 23 & 195 & 239 & 239 \\
\hline 8 & 215 & 196 & 196 & 25 & 75 & -80 & -80 \\
\hline 10 & 215 & 189 & $\begin{array}{l}190 \\
189\end{array}$ & 26 & 104 & 122 & 122 \\
\hline 11 & $\begin{array}{l}100 \\
155\end{array}$ & $\begin{array}{r}189 \\
-121\end{array}$ & $\begin{array}{r}189 \\
-121\end{array}$ & 28 & 99 & 118 & 118 \\
\hline 13 & 325 & 330 & $\begin{array}{r}-121 \\
\mathbf{3 3 0}\end{array}$ & 29 & 87 & -75 & -75 \\
\hline 14 & 333 & 321 & 321 & 31 & 195 & 210 & 210 \\
\hline 16 & 110 & -106 & -106 & 32 & 180 & 207 & 207 \\
\hline 17 & 157 & 158 & 158 & & & & \\
\hline 19 & 132 & 151 & 151 & $30 . l$ & & & \\
\hline 20 & 95 & -97 & -97 & 0 & 499 & 433 & 612 \\
\hline 22 & 254 & 266 & 266 & 9 & 437 & 416 & 588 \\
\hline 23 & 240 & 260 & 260 & 18 & 394 & 384 & 556 \\
\hline 25 & 81 & -86 & -86 & 27 & 291 & 342 & 411 \\
\hline 26 & 104 & 130 & 130 & & & & \\
\hline 28 & 105 & 125 & 125 & $40 . l$ & & & \\
\hline 29 & 83 & -80 & -80 & 1 & 101 & 117 & \\
\hline 31 & 224 & 223 & 223 & 2 & 66 & -76 & -76 \\
\hline 32 & 219 & 219 & 219 & 4 & 198 & 219 & 219 \\
\hline 34 & 72 & -73 & -73 & 5 & 196 & 218 & 218 \\
\hline \multirow[t]{2}{*}{35} & 101 & 110 & 110 & 7 & 64 & -75 & -75 \\
\hline & & & & 8 & 86 & 115 & 115 \\
\hline $20 . l$ & & & & 10 & 93 & 114 & 114 \\
\hline 1 & 168 & 170 & 170 & 11 & 59 & -74 & -74 \\
\hline 2 & 143 & -111 & -111 & 13 & 158 & 209 & 209 \\
\hline 4 & 331 & 315 & 315 & 14 & 133 & 207 & 207 \\
\hline 5 & 332 & 312 & 312 & & & & \\
\hline
\end{tabular}
and the random structure*

* The observed systematic absences of the $(h 0 . l)$ data are not listed since the calculated structure factors are identically zero.

$\dagger F_{R}$ denotes the calculated structure factors for a random arrangement $(A=0)$ of the two structures. 


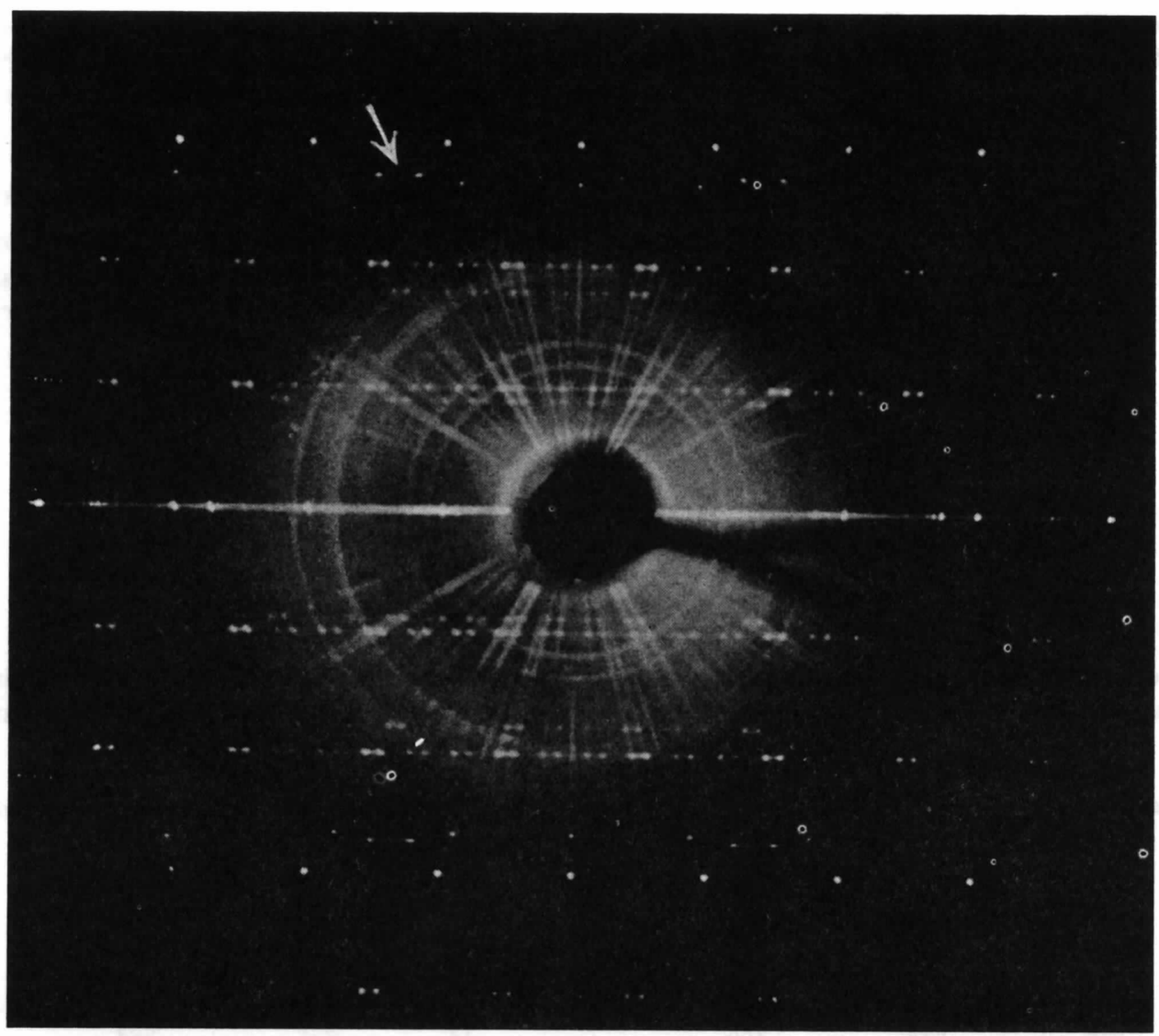

Fig. 1. Precession photograph of the $(h 0 . l)$ reflections showing the disorder streaking in the $c$ direction using unfiltered Mo radiation. The arrow indicates reflections due to $\mathrm{Fe} K \alpha$ radiation.

$\mathrm{X}$-ray photographs is too high. Table 1 shows, however, that if this structure is combined with an identical one except for rotation of $180^{\circ}$ about the $c$ axis, good agreement with the observed data is obtained.

A macroscopically twinned crystal could give the above results if each twin were present in equal amounts, but there was no visible evidence in favor of this. Also, such a crystal would not explain the observed streaking which is believed due to a disordered structure.

It was first assumed that the crystal consisted of a random arrangement of the two structures, $(A=0$, in the notation below, Hendricks \& Teller, 1942), but the calculated structure factors for the Type I reflections were then too large by a factor of $/ 2$. However, the experimental data can be explained very satisfactorily if one assumes an approach to complete ordering of like layers $\left(A \cong \frac{1}{4}\right)$. (Since $A \cong \frac{1}{4}$, an alternative description in terms of submicroscopic twinning is also appropriate.)

The crystal is considered to be built of layers where each layer is one unit cell (nine close-packed layers) thick in the $c$ direction. Half of the layers contain one type of unit cell and half contain the other type (see above). Hendricks \& Teller (1942) derived the following formula for this particular case in $\S 4$ of their article giving the intensity of the scattered radiation:

$$
\begin{aligned}
I_{\text {av. }}=I_{1}+I_{2} & =\sum_{k=-\infty}^{\infty}\left[\left(V_{1}+V_{2}\right) / 2\right]^{2} \cos k \varphi \\
& +\sum_{k=-\infty}^{\infty}\left[\left(V_{1}-V_{2}\right) / 2\right]^{2}(4 A)^{k} \cos k \varphi .
\end{aligned}
$$

$V_{1}$ and $V_{2}$ are the structure amplitudes for the two types of layers; $\varphi$ is the phase shift between neighboring layers and is assumed constant. $A$ is a measure of the probability of neighboring layers being alike or unlike, and may be positive, corresponding to a tendency of like layers being nearest neighbors, or negative, corresponding to a tendency of unlike layers being nearest neighbors. If $A=0$ there is no correlation between the layers. The first term in equation (1) gives the intensity of the ordered scattering. The second term gives the intensity of the disordered scattering and is equal to

$$
I_{2}=\left[\frac{\left(V_{1}-V_{2}\right)}{2}\right]^{2} \frac{1-(4 A)^{2}}{1-2(4 A) \cos \varphi+(4 A)^{2}} .
$$


For $A=\frac{1}{4}$ the crystal consists of regions containing exclusively one or the other kind of layer. If $\varphi=2 \pi n$, equation (2) gives sharp interference maxima in the same positions as the maxima of the ordered scattering and the intensities are proportional to $\left[\left(V_{1}-V_{2}\right) / 2\right]^{2}$. The total intensity of the reflections is proportional to $\left[\left(V_{1}+V_{2}\right) / 2\right]^{2}+\left[\left(V_{1}-V_{2}\right) / 2\right]^{2}$, which is the average intensity of two crystals with the structure amplitudes $V_{1}$ and $V_{2}$. The calculated structure amplitudes for this structure and the random structure are compared with those observed in Table 2.

Since there are two types of layers, $A$ cannot be exactly 1 and some disorder streaking is expected near the reflections where $h-k \neq 3 n$, and the streaking will be more intense near the stronger reflections. For those reflections where $h-k=3 n,\left[\left(V_{1}-V_{2}\right) / 2\right]^{2}$ is zero and no streaking should be observed. That this is the case may be seen in Fig. 1. The streaking between the (10.4) and (10.5) reflections appears to be stronger than one would expect in comparison to the streaking between the other reflections, but this can be explained by considering the boundaries of the regions where a superlattice with a repeat period of eighteen close-packed layers is formed by the two different layers. One would then expect maxima to lie between the regular reflections, but they would be diffuse owing to the fact that the size of diffracting regions is small. The streaking between the $(10.4)$ and (10.5) reflections would correspond to the reflection (10.9) of the larger unit cell, and indeed the calculated intensity of this reflection is five times stronger than any other superlattice reflection.

\section{Discussion}

Samarium is one of the few rare earths with a relatively stable valence of +2 . Whether the stability of such a state is reflected in the metal is a matter of some interest. According to Pauling's theory of valence (1947) the number of valence electrons should materially influence bond distances, so that any contribution to the metal of +2 rather than +3 valence should increase the metal-metal distance and reduce the density of samarium relative to the normal sequence of rare earth metals. As nearly as can be judged there is no such effect, so that the metallic valence of samarium is probably close to three.

It is not known why the structure of samarium deviates from a cubic or hexagonal close-packed arrangement but it is not the only rare earth metal which does so. Klemm \& Bommer (1939) reported evidence (they referred to K. Meisel's work) requiring the $c$ axis of praseodymium and neodymium to be doubled. This has been confirmed for neodymium by Ellinger \& Zachariasen and by us. In this case the packing sequence is $a b c b$.

\section{References}

DaAne, A. H., Dennison, D. H. \& Spedding, F. H. (1953). J. Amer. Chem. Soc. 75, 2272.

Ellinger, F. H. \& Zachariasen, W. H. (1953). J. Amer. .Chem. Soc. 75, 5650.

Hendricks, S. B. \& Tellek, E. (1942). J. Chem. Phys. $10,147$.

KLEMM,W. \& Bommer, H. (1939). Z. anorg. Chem. 241, 264. Pauling, L. (1947). J. Amer. Chem. Soc. 69, 542.

Acta Cryst. (1954). 7, 535

\title{
The Geometrical Basis of Crystal Chemistry. Part 1
}

\author{
By A. F. WeLLS \\ Imperial Chemical Industries Limited (Dyestuffs Division), Hexagon House, Manchester 9, England
}

(Received 1 January 1954 and in revised form 1 April 1954)

An investigation is made of the periodic three-dimensional systems of points in which each point is connected to three others. These nets form the bases of the structures of a large number of crystals in which there are directed bonds or hydrogen bonds.

\section{Introduction}

The principles underlying the crystal structures of some groups of compounds, for example, ionic, molecular, and the simpler metallic systems, are known at least in broad outline. Less attention seems to have been paid to the large class of crystals whose structures are determined by systems of directed bonds extending indefinitely in one, two, or three dimensions. These include: many non-metallic and 'semi-metallic' elements; oxides of some non-metals; oxides, halides and sulphides of some less electropositive and $B$ subgroup metals; certain borides, carbides and silicides; and some oxy-salts and complex oxides (e.g. silicates). The other major group of crystal structures to be regarded in this way embraces all hydrogen-bonded molecular crystals. The atoms taking part in the hydrogen bonding act, from the structural point of view, like localized charges and result in limited numbers of relatively close intermolecular contacts. 